\title{
Effects of Canagliflozin on Fatty Liver Indexes in Patients with Type 2 Diabetes: A Meta-analysis of Randomized Controlled Trials
}

\author{
Boyu $\mathrm{Li}^{1}$, Ying Wang ${ }^{1}$, Zhikang Ye ${ }^{1}$, Hui Yang ${ }^{1}$, Xiangli Cui ${ }^{1}$, Zhenjun Wang ${ }^{2}$, Lihong Liu ${ }^{1}$ \\ ${ }^{1}$ Department of Pharmacy, Beijing Chao-Yang Hospital, Capital Medical University, Beijing, China. ${ }^{2}$ Department of \\ General Surgery, Beijing Chao-Yang Hospital, Capital Medical University, Beijing, China.
}

Received, March 5, 2018; Revised, June 7, 2018; Accepted, June 20, 2018; Published, June 21, 2018.

\begin{abstract}
PURPOSE: Non-alcoholic fatty liver disease (NAFLD) affects about $75 \%$ of patients with type 2 diabetes mellitus (T2DM). We conducted a meta-analysis to determine the effect of canagliflozin on fatty liver indexes in T2DM patients. METHODS: A literature search of PubMed, Embase and Cochrane was conducted up to March 30, 2017. The liver function test and lipid profile were extracted from randomized controlled trials (RCTs) to evaluate the effect of canagliflozin on fatty liver. Weighted mean differences (WMDs) or relative risks and $95 \%$ confidence intervals (CIs) were computed by using either fixed or randomeffects models. Sensitivity analysis and publication bias were evaluated. RESULTS: Our results showed that canagliflozin decreased serum concentrations of alanine amino transferase (WMD: -11.68 [95\% CI: -18.95, -10.95]; $P<0.001$ ), aspartate amino transferase (WMD: -7.50 [95\% CI: $-10.61,-4.38$ ]; $P<0.001$ ), gammaglutamyl transferase (WMD: -15.17 [95\% CI: $-17.73,-12.61]$; $P<0.001$ ), triglycerides (WMD: -0.10 [95\% CI: $-0.15,-0.05] ; P<0.001$ ) but increased low-density lipoprotein cholesterol (WMD: 0.1 [95\% CI: 0.06, 0.13]; $P<0.001$ ), high-density lipoprotein cholesterol (WMD: 0.06 [95\% CI: 0.05, 0.07]; $P<0.001$ ) at week 26 or 52 . CONCLUSIONS: Our results indicated that canagliflozin may have a protective effect on fatty liver in T2DM patients. The limitation was that the liver biopsy was hard to obtain in published studies. More RCTs specified on NAFLD are needed to get further information.
\end{abstract}

This article is open to POST-PUBLICATION REVIEW. Registered readers (see "For Readers") may comment by clicking on ABSTRACT on the issue's contents page.

\section{INTRODUCTION}

Type 2 diabetes mellitus (T2DM) is a chronic and progressive metabolic disease that is associated with comorbidities, including non-alcoholic fatty liver disease (NAFLD) (1). NAFLD shared some pathogenetic requisites with T2DM, such as obesity and insulin resistance (2), and affects about $75 \%$ of patients with T2DM (3). The prognosis for patients with concomitant NAFLD and T2DM is worsened due to increased risk for life-threatening sequela such as cardiovascular disease and hepatocellular carcinoma (4). Therefore, antidiabetic drugs which have effect on improving NAFLD would be beneficial and suitable for T2DM patients with NAFLD.

Canagliflozin is a sodium glucose co-transporter 2 (SGLT2) inhibitor developed for the treatment of adults with T2DM (5). Canagliflozin promotes urinary glucose excretion, resulting in decreased plasma glucose, a mild osmotic diuresis and a net caloric loss $(6,7)$. Canagliflozin provides improvements in glycosylated hemoglobin, body weight and systolic blood pressure, and is generally well tolerated. Studies which assessed the effects of SGLT2 inhibitors on hepatic steatosis suggested the potential application of this class for the treatment of $\operatorname{NAFLD}(8,9)$.

Several previous research suggeted that canagliflozin might benefit NAFLD. Shiba K et al. found that canagliflozin attenuated the development of hepatocellular carcinoma in a mouse model of human non-alcoholic steatohepatitis (10). Seko Y et al. conducted a retrospective study and found SGLT2 inhibitors significantly decreased the transaminase activities in Japanese patients with NAFLD and T2DM (11). Takase T et al. conducted an observational study in Japanese patients with T2DM, and found that ipragliflozin significantly decreased body mass index, waist circumference, gamma-glutamyl transferase and triglycerides (12).

Corresponding Author: Lihong Liu, E-mail: liulihong@bjcyh.com, Gongtinan Road, Chaoyang District, Beijing, China; Zhenjun Wang, E-mail: drzhenjun@163.com, Gongtinan Road, Chaoyang District, Beijing, China. 


\begin{abstract}
ABBREVIATIONS: NAFLD $=$ non-alcoholic fatty liver disease; $\mathrm{T} 2 \mathrm{DM}=$ type 2 diabetes mellitus; $\mathrm{WMD}=$ weighted mean difference; $\mathrm{CI}=95 \%$ confidence interval; $\mathrm{ALT}=$ alanine amino transferase; $\mathrm{AST}=$ aspartate amino transferase; GGT=gamma-glutamyl transferase; ALP= alkaline phosphatase; $\mathrm{TG}=$ triglycerides; $\mathrm{HDL}=$ high-density lipoprotein; $\mathrm{LDL}=$ lowdensity lipoprotein; SGLT2=sodium glucose cotransporter 2; RCT = randomized controlled trials; $\mathrm{RR}=$ relative risk
\end{abstract}

However, these studies are not randomized controlled trials and mainly Japanese population. Currect meta-analysis associated with SGLT2 inhibitors only mentioned lipid or alanine amino transferase (ALT) and didn't take them as main outcomes (13-15). So we conducted a meta-analysis to evaluate the effect of canagliflozin on NAFLD through liver function and lipid profile.

\section{METHODS}

\section{Search strategy and selection of articles}

We searched PubMed, EMBASE, Cochrane Central Register of Controlled Trials (CENTRAL) and ClinicalTrials.gov databases up to March 30, 2017 to identify eligible randomized controlled trials (RCTs) using keyword combinations of ("Sodium glucose co-transporter" OR SGLT2 OR SGLT-2 OR "SGLT 2" OR Tofogliflozin OR Apleway OR Deberza OR CSG452 OR Empagliflozin OR Jardiance OR dapagliflozin OR Farxiga OR Forxiga OR Canagliflozin OR Invokana OR Sotagliflozin OR LX4211 OR luseogliflozin OR Lusefi OR Ipragliflozin OR Suglat OR remogliflozin OR BHV091009 OR sergliflozin OR GW869682X OR ertugliflozin OR MK-8835 OR PF-04971729) AND (RCT OR random). Only human studies were included. Two reviewers ( $\mathrm{Li}$ B, Wang Y) independently screened titles and/or abstracts for relevance followed by full-text article assessments for inclusion. Studies were included if: (1) The participants were non-pregnant adults (aged over 18 years) with T2DM. (2) The treatment intervention was canagliflozin monotherapy or combination therapy with any approved agent or not. (3) The study design was randomized, double-blind, placebo-controlled, or active-controlled, parallelgroup study. Articles were excluded if they were letters, editorials, conference abstracts, reviews, and commentaries. For multiple publications in the same RCT, only the article with the most comprehensive data was included. Searching results are depicted in Figure 1.
Citations retrieved from electronic databases $(n=4434)$, including:

PubMed ( $=1138)$, Embase $(n=2551)$, Cochrane $(\mathrm{n}=745)$, ClinicalTrials.gov registry $(n=0)$

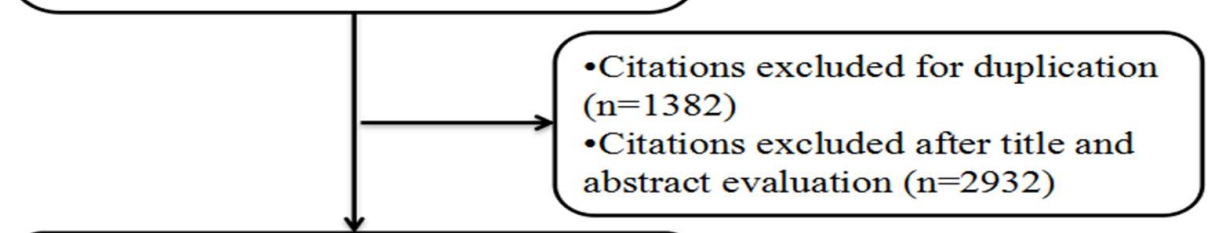

Full texts of potential trials were retrieved for further evaluation $(\mathrm{n}=120)$

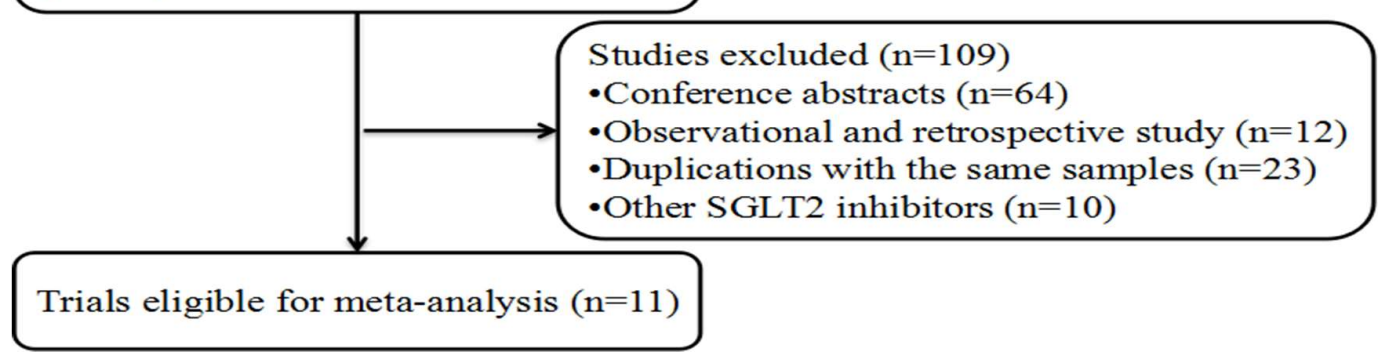

Figure 1. Summary of study identification, inclusion, and exclusion. 


\section{Quality assessment of the trials}

The quality of RCTs was assessed with the Cochrane risk of bias tool, which is the recommended approach for assessing the risk of bias in studies included in Cochrane reviews. This tool assesses the risk of bias in 2 parts, addressing the following specific domains: sequence generation, allocation concealment, blinding of participants and personnel, blinding of outcome assessment, incomplete outcome data, selective outcome reporting, and other issues (16).

\section{Data extraction}

Two reviewers ( $\mathrm{Li} \mathrm{B}$, Wang $\mathrm{Y}$ ) independently extracted relevant information for the meta-analysis. The extracted data included the characteristics of each study (author, year, study design, treatment, mean age, race, mean glycosylated hemoglobin and follow-up time), and clinical outcomes (change percentage of alanine amino transferase (ALT), aspartate amino transferase (AST), gamma-glutamyl transferase (GGT), alkaline phosphatase (ALP), triglycerides (TG), high-density lipoprotein (HDL), low-density lipoprotein (LDL), LDL/HDL, nonHDL cholesterol) of the control and canagliflozin groups in each study. Two authors separately performed data extraction. The differences were discussed and resolved.

\section{Data synthesis and statistical analysis}

To synthesize the efficacy outcomes, Review Manager 5 (The Cochrane Collaboration, Oxford, UK) was used to calculate the estimates and 95\% confidence intervals (CIs) of the weighted mean differences (WMDs) between the intervention group (canagliflozin 100 or $300 \mathrm{mg}$ daily) and the control group for quantitative variables and relative risks (RRs) for categorical variables, using either fixed or random effects models with an inverse variance method.

$P$ values less than 0.05 were considered statistically significant. Heterogeneity among the trials was assessed using the $\chi^{2}$ test defined as a $P$ value less than 0.10 and was further quantified through the $I^{2}$ statistics. In order to evaluate the stability of results without estimation bias from individual study, sensitivity analysis was performed by exclusion of each study one by one. This process of excluding one study at a time allowed for identification of any single article that might have a large influence on the final results. Publication bias was evaluated using the funnel plot method.

\section{RESULTS}

\section{Literature search and characteristics of the included studies}

The search strategy initially identified 4434 articles. After selection, 11 randomized, double-blind, placebo-controlled or active-controlled, parallelgroup trials met the selection criteria, with a total enrollment of 6745 patients with T2DM. The whole literature search process was summarized in Figure 1. Characteristics of the included studies were presented in Table 1. Baseline liver function and lipid profile of included studies were presented in Table 2.

\section{Liver function \\ ALT}

At week 26 and 52, canagliflozin $100 \mathrm{mg}$ and 300mg all significantly reduced the ALT from baseline compared with the control group (26 week/100mg: WMD $\quad-7.39 \quad\left[\begin{array}{llll}95 \% & \text { CI: } & -13.80, & -0.98\end{array}\right], 26$ week/300mg: WMD -10.30[95\% CI: -17.17, -3.42], 52 week/100mg:WMD -11.05 [95\% CI: -16.47 , 5.64], 52 week/300mg: WMD -14.95 [95\% CI: $18.95,-10.95])$, with a WMD of -11.68 [95\% CI: $14.45,-8.91]$ for the total $(P<0.001)$ (Fig.2a).

\section{AST}

At week 52, canagliflozin $100 \mathrm{mg}$ and $300 \mathrm{mg}$ both significantly reduced the AST from baseline compared with the control group (52 week/100mg:WMD -9.85 [95\% CI: -13.82, -5.88], 52 week/300mg: WMD -11.35 [95\% CI: -15.46, 7.23]. The WMD is -7.50 [95\% CI: $-10.61,-4.38$ ] for the total $(P<0.001)$ (Fig.2b).

\section{GGT}

At week 26 and 52, canagliflozin $100 \mathrm{mg}$ and 300mg significantly reduced the GGT from baseline compared with the control group (26 week/100mg: WMD $-16.00 \quad[95 \%$ CI: $-22.97,-9.03], 26$ week/300mg: WMD -12.60[95\% CI: -20.32, -4.88], 52 week/100mg:WMD -13.99 [95\% CI: -18.42, 9.56], 52 week/300mg: WMD -16.50 [95\% CI: $20.45,-12.56])$, with a WMD of -15.17 [95\% CI: $17.73,-12.61]$ for the total $(P<0.001)$ (Fig.2c).

\section{ALP}

There is a decreasement of ALP with a WMD of 1.52[95\% CI: $-2.56,-0.48](P<0.01)$ (Suppl Fig.1). 


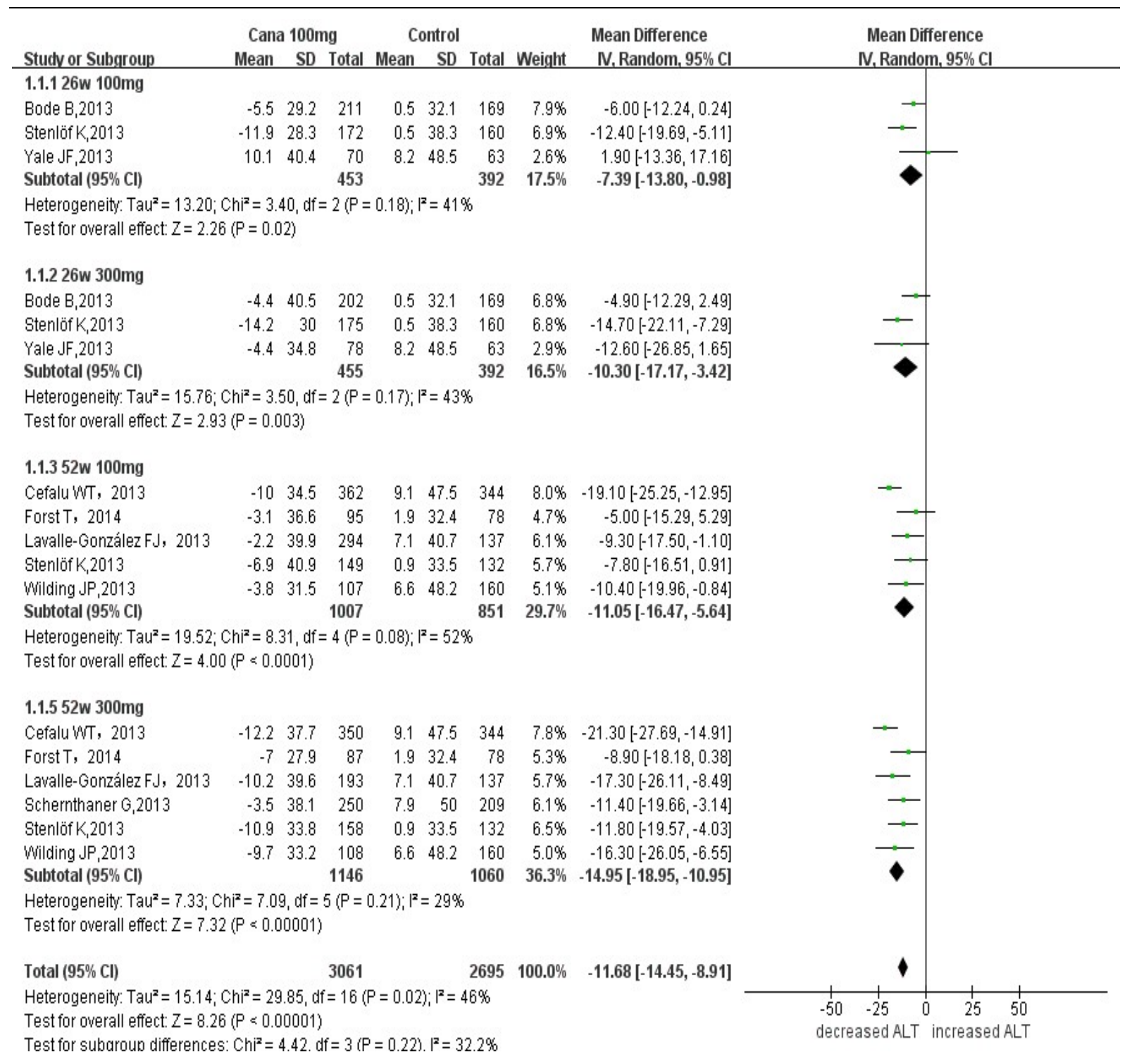

Figure 2a. Forest plot depicting the ALT level with canagliflozin versus control group.

\section{Lipid profile}

\section{TG}

At week 12-18, no change was abserved. At week 26, canagliflozin $100 \mathrm{mg}$ and $300 \mathrm{mg}$ both reduced the TG from baseline compared with the control group (26 week/100mg: WMD -0.12 [95\% CI: -0.22, 0.02 ], 26 week/300mg: WMD -0.13[95\% CI: -0.23, -0.03]). At week 52, canagliflozin $100 \mathrm{mg}$ decrease the TG level with a WMD of $-0.16[95 \% \mathrm{CI}:-0.29$, $0.02]$ (Fig.3a). There is a decreasement of TG with a WMD of -0.10 [95\% CI: $-0.15,-0.05]$ for the total $(P<0.001$.

\section{LDL-C}

At week 12-18, no change was abserved. At week 26, canagliflozin $100 \mathrm{mg}$ and $300 \mathrm{mg}$ both increased the LDL-C from baseline compared with the control group (26 week/100mg: WMD 0.08 [95\% CI: 0.01, 0.16], 26 week/300mg: WMD 0.15[95\% CI: 0.08, $0.23]$ ). At week 52, canagliflozin $300 \mathrm{mg}$ increased the TG level with a WMD of 0.13 [95\% CI: 0.07 , $0.19]$. There is an increasement of LDL-C with a WMD of 0.1 [95\% CI: 0.06, 0.13] for the total $(P<0.001)$ (Fig.3b). 


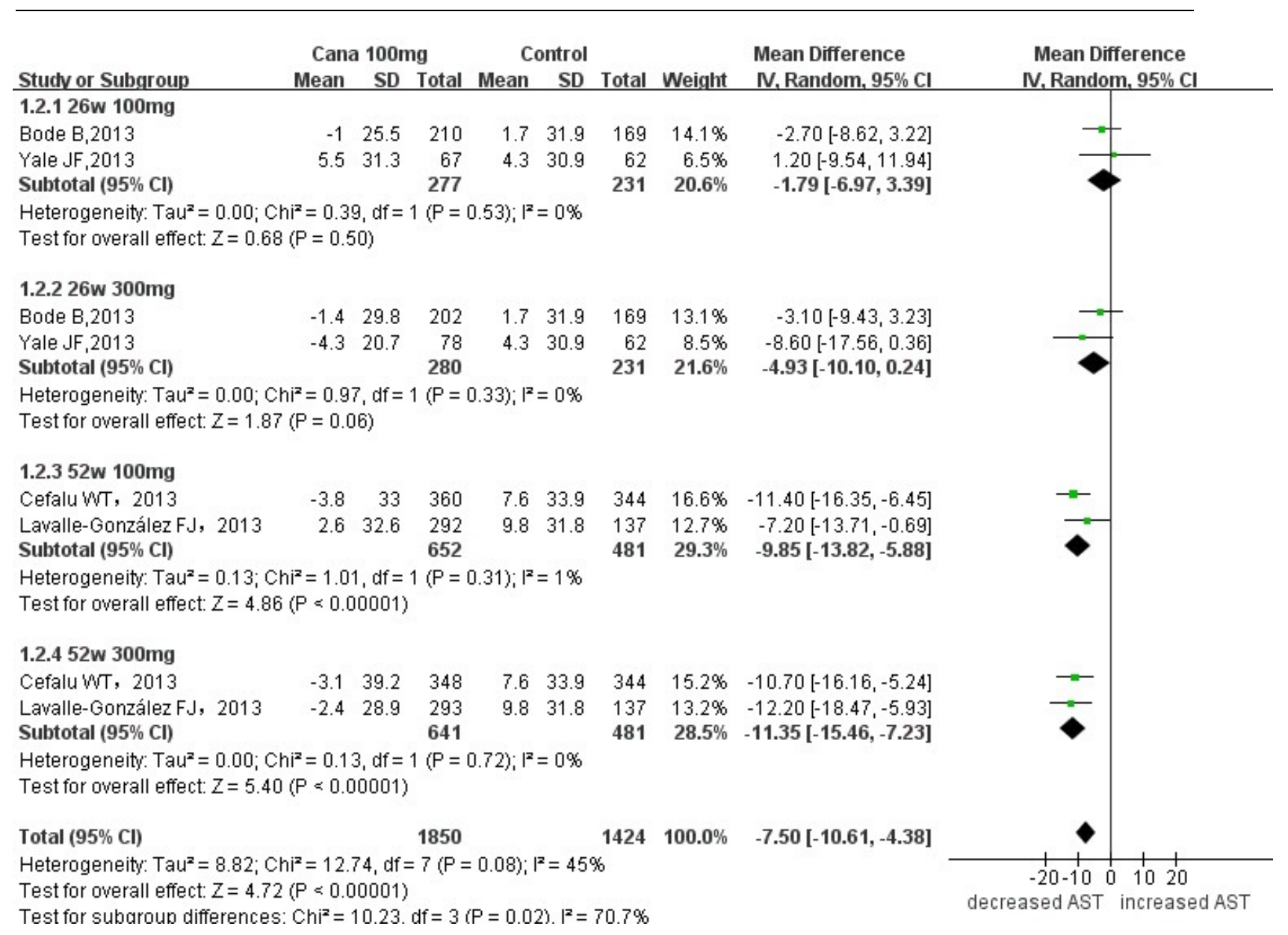

Figure 2b. Forest plot depicting the AST level with canagliflozin versus control group.

\section{HDL-C}

At week 12-18, no obvious change was abserved. At week 26 and 52, canagliflozin $100 \mathrm{mg}$ and $300 \mathrm{mg}$ both increased the HDL-C from baseline compared with the control group (26 week/100mg: WMD 0.05 [95\% CI: 0.03, 0.08], 26 week $/ 300 \mathrm{mg}:$ WMD 0.05[95\% CI: $0.03,0.08], 52$ week/100mg:WMD 0.07 [95\% CI: 0.04, 0.09], 52 week/300mg: WMD 0.09 [95\% CI: 0.07, 0.10]). There is an increasement of HDL-C with a WMD of 0.06 [95\% CI: 0.05, 0.07] for the total $(P<0.001)$ (Fig.3c).

\section{LDL/HDL ratio}

There is a decreasement of LDL/HDL ratio with a WMD of -0.04 [95\% CI: $-0.07,-0.01]$ for the total $(P<0.01)$ (Suppl Fig.2).

\section{Non-HDL Cholesterol}

There is an increasement of non-HDL cholesterol with a WMD of 0.06 [95\% CI: 0.02, 0.09] for the total $(P<0.01)$ (Suppl Fig.3).

\section{DISCUSSION}

The main findings of this meta-analysis included two parts. First, canagliflozin significanltly decreased serum concentrations of ALT, AST and GGT at week 26 and 52, indicating it might have a protective effect on liver. Second, canagliflozin reduced TG but increased LDL-C and HDL-C levels at week 26 and 52, which was consistant with previous meta-analysis, but a little confusing. There is no doubt that fasting plasma TG was pravently investigated and tightly related with NAFLD (17, 18). While no benefits or harm of Statins were observed on liver disease although they are confidently used to reduce LDL-cholesterol and prevent cardiovascular risk (19). So the reduced TG level of our meta-analysis indicated canagliflozin might be helpful to NAFLD. 


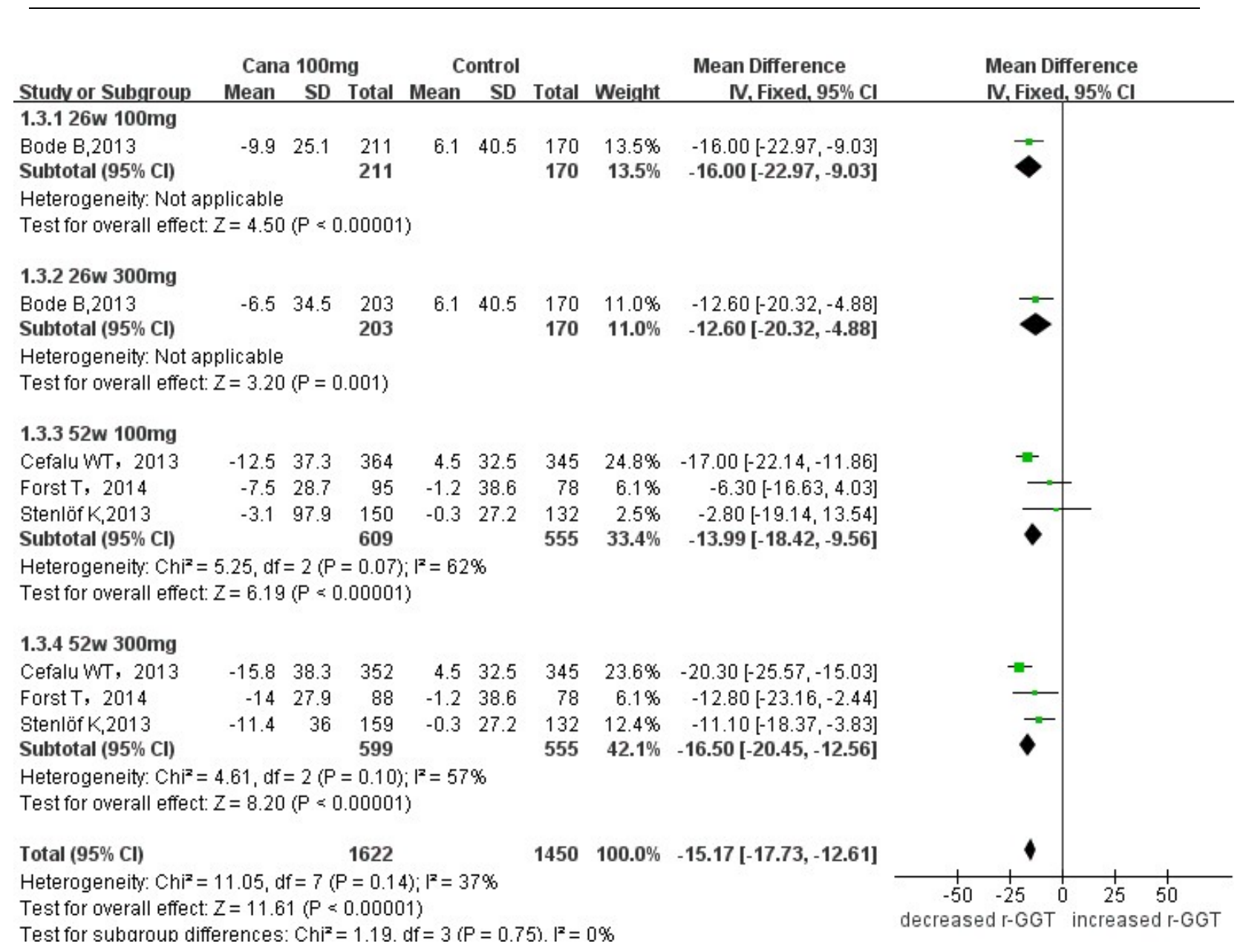

Figure 2c. Forest plot depicting the GGT level with canagliflozin versus control group.

How did canagliflozin affect LDL and HDL cholesterol level? In a study of hamsters with dietinduced dyslipidemia, Briand $\mathrm{F}$ et al. found empagliflozin moderately increased ketone production and LDL cholesterol levels by switching energy metabolism from carbohydrate to lipid utilization. The catabolism of (3)H-cholesteryl oleate-labeled LDL cholesterol injected intravenously was significantly reduced by $20 \%$, indicating that empagliflozin reduced intestinal cholesterol absorption (20). Canagliflozin may raise LDL cholesterol levels through the same mechanism with empagliflozin, which are the reduced catabolism and reduced intestinal absorption.

What kind of LDL and HDL cholesterol subspecies did SGLT-2 inhibitors affect? Hayashi $\mathrm{T}$ et al. conducted a single center, open-label, randomized, prospective study in human to determine how SGLT-2 inhibitors affect LDL and
HDL cholesterol subspecies. They found that dapagliflozin suppresses potent atherogenic small dense LDL cholesterol and increased HDL2 cholesterol, a favorable cardiometabolic marker. In their opinion, the elevated level of LDL cholesterol levels after treatment with dapagliflozin was due to increased concentrations of the less atherogenic large buoyant LDL cholesterol (21).

The results of our meta-analysis were consistent with the previous three meta-analysis, two of which only analyzed lipid change after canagliflozin treatment $(13,14)$ and the third one analyzed lipid and ALT only (15). Compared to these studies, the advantage of our study was that: 1) We focused on the effect of canagliflozin on the fatty liver indexes; 2) We made an analysis on the reason why LDL and HDL cholesterol were elevated and the meaning of this change to cardiovascular risk. 


\begin{tabular}{|c|c|c|c|c|c|c|c|c|c|c|}
\hline \multirow[b]{2}{*}{ Studv or Subgroup } & \multicolumn{3}{|c|}{ Cana 100mg } & \multicolumn{2}{|c|}{ Control } & \multirow[b]{2}{*}{ Total } & \multirow[b]{2}{*}{ Weight } & \multirow{2}{*}{$\begin{array}{c}\text { Mean Difference } \\
\text { IV, Fixed, } 95 \% \mathrm{Cl}\end{array}$} & \multirow{2}{*}{\multicolumn{2}{|c|}{$\begin{array}{l}\text { Mean Difference } \\
\text { IV, Fixed, 95\% Cl }\end{array}$}} \\
\hline & Mean & SD & Total & Mean & SD & & & & & \\
\hline \multicolumn{11}{|l|}{ 2.1.1 12w 100mg } \\
\hline Rosenstock J,2012 & -0.2 & 1.13 & 64 & -0.13 & 1.13 & 64 & $1.5 \%$ & $-0.07[-0.46,0.32]$ & & \\
\hline Subtotal $(95 \% \mathrm{Cl})$ & & & 64 & & & 64 & $1.5 \%$ & $-0.07[-0.46,0.32]$ & & \\
\hline \multicolumn{11}{|c|}{ Heterogeneity: Not applicable } \\
\hline \multicolumn{11}{|c|}{ Test for overall effect: $Z=0.35(P=0.73)$} \\
\hline \multicolumn{11}{|l|}{$2.1 .212 w 300 \mathrm{mg}$} \\
\hline Rosenstock J,2012 & -0.32 & 1.14 & 65 & -0.13 & 1.13 & 64 & $1.5 \%$ & $-0.19[-0.58,0.20]$ & & \\
\hline Subtotal $(95 \% \mathrm{Cl})$ & & & 65 & & & 64 & $1.5 \%$ & $-0.19[-0.58,0.20]$ & & \\
\hline \multicolumn{11}{|c|}{ Heterogeneity: Not applicable } \\
\hline \multicolumn{11}{|c|}{ Test for overall effect: $Z=0.95(P=0.34)$} \\
\hline \multicolumn{11}{|l|}{ 2.1.3 16w 100mg } \\
\hline Inagaki N,2016 & -0.09 & 0.72 & 75 & -0.05 & 0.73 & 70 & $4.3 \%$ & $-0.04[-0.28,0.20]$ & & \\
\hline Subtotal $(95 \% \mathrm{Cl})$ & & & 75 & & & 70 & $4.3 \%$ & $-0.04[-0.28,0.20]$ & & \\
\hline Heterogeneity: Not app & icable & & & & & & & & & \\
\hline Test for overall effect: $z$ & $=0.33(\mathrm{P}$ & $=0.74$ & & & & & & & & \\
\hline 2.1.4 18w 100mg & & & & & & & & & & \\
\hline Qiu R, 2014 & -0.02 & 0.85 & 90 & -0.06 & 0.84 & 88 & $3.9 \%$ & $0.04[-0.21,0.29]$ & & \\
\hline Subtotal $(95 \% \mathrm{Cl})$ & & & 90 & & & 88 & $3.9 \%$ & $0.04[-0.21,0.29]$ & & \\
\hline Heterogeneity: Not app & icable & & & & & & & & & \\
\hline Test for overall effect: $z$ & $=0.32(\mathrm{P}$ & $=0.75$ & & & & & & & & \\
\hline $2.1 .518 w 300 \mathrm{mg}$ & & & & & & & & & & \\
\hline Qiu R, 2014 & 0 & 0.84 & 88 & -0.06 & 0.84 & 88 & $3.9 \%$ & $0.06[-0.19,0.31]$ & & \\
\hline Subtotal $(95 \% \mathrm{Cl})$ & & & 88 & & & 88 & $3.9 \%$ & $0.06[-0.19,0.31]$ & & \\
\hline Heterogeneity: Not app & icable & & & & & & & & & \\
\hline Test for overall effect: $z$ & $=0.47(\mathrm{P}$ & $=0.64$ & & & & & & & & \\
\hline 2.1.6 26w 100mg & & & & & & & & & & \\
\hline Bode $B, 2013$ & -0.05 & 1.05 & 227 & 0 & 1 & 206 & $6.4 \%$ & $-0.05[-0.24,0.14]$ & & \\
\hline Forst T, 2014 & -0.06 & 0.83 & 108 & 0.1 & 0.82 & 105 & $4.8 \%$ & $-0.16[-0.38,0.06]$ & $\rightarrow$ & \\
\hline Stenlöf $K_{2} 2013$ & -0.16 & 0.95 & 183 & 0.07 & 0.92 & 171 & $6.3 \%$ & $-0.23[-0.42,-0.04]$ & $\rightarrow$ & \\
\hline Wilding JP,2013 & 0.02 & 1.08 & 145 & 0.12 & 1.04 & 134 & $3.8 \%$ & $-0.10[-0.35,0.15]$ & $\longrightarrow$ & \\
\hline Yale JF,2013 & 0.02 & 1 & 82 & -0.01 & 0.95 & 75 & $2.6 \%$ & $0.03[-0.28,0.34]$ & 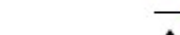 & \\
\hline Subtotal $(95 \% \mathrm{Cl})$ & & & 745 & & & 691 & $23.8 \%$ & $-0.12[-0.22,-0.02]$ & & \\
\hline Heterogeneity: $\mathrm{Chi}^{2}=2$ & $81, d f=4$ & $4(P)=0$ & $.59) ;\left.\right|^{2}$ & $=0 \%$ & & & & & & \\
\hline Test for overall effect: $z$ & $=2.34(\mathrm{P}$ & $=0.02$ & & & & & & & & \\
\hline $2.1 .726 \mathrm{w} 300 \mathrm{mg}$ & & & & & & & & & & \\
\hline Bode B,2013 & -0.03 & 1.04 & 222 & 0 & 1 & 206 & $6.4 \%$ & $-0.03[-0.22,0.16]$ & - & \\
\hline Forst T, 2014 & -0.16 & 0.84 & 109 & 0.1 & 0.82 & 105 & $4.8 \%$ & $-0.26[-0.48,-0.04]$ & $\rightarrow$ & \\
\hline Stenlöf $K_{2} 2013$ & -0.18 & 0.95 & 183 & 0.07 & 0.92 & 171 & $6.3 \%$ & $-0.25[-0.44,-0.06]$ & $\rightarrow$ & \\
\hline Wilding JP,2013 & -0.07 & 1.07 & 142 & 0.12 & 1.04 & 134 & $3.8 \%$ & $-0.19[-0.44,0.06]$ & $\rightarrow$ & \\
\hline Yale JF, 2013 & 0.22 & 1.01 & 85 & -0.01 & 0.95 & 75 & $2.6 \%$ & $0.23[-0.07,0.53]$ & & \\
\hline Subtotal $(95 \% \mathrm{Cl})$ & & & 741 & & & 691 & $23.8 \%$ & $-0.13[-0.23,-0.03]$ & $\checkmark$ & \\
\hline Heterogeneity: $\mathrm{Chi}^{2}=$ & $41, d f=4$ & $4(P=0$ & $.05) ;\left.\right|^{2}$ & $=58 \%$ & & & & & & \\
\hline Test for overall effect: $z$ & $=2.59(\mathrm{P}$ & $=0.01$ & & & & & & & & \\
\hline $2.1 .852 w 100 m g$ & & & & & & & & & & \\
\hline Cefalu WT, 2013 & -0.22 & 1.29 & 465 & -0.01 & 1.08 & 466 & $10.2 \%$ & $-0.21[-0.36,-0.06]$ & $\leadsto$ & \\
\hline Wilding JP,2013 & 0.04 & 1.2 & 145 & 0.03 & 1.16 & 134 & $3.1 \%$ & $0.01[-0.27,0.29]$ & & \\
\hline Subtotal $(95 \% \mathrm{Cl})$ & & & 610 & & & 600 & $13.3 \%$ & $-0.16[-0.29,-0.02]$ & & \\
\hline Heterogeneity: $\mathrm{Chi}^{2}=1$ & $86, d f=1$ & $1(P=0$ & $17) ; i^{2}=$ & $=46 \%$ & & & & & & \\
\hline Test for overall effect: $z$ & $=2.32(\mathrm{P}$ & $=0.02$ & & & & & & & & \\
\hline $2.1 .952 \mathrm{w} 300 \mathrm{mg}$ & & & & & & & & & & \\
\hline Cefalu WT, 2013 & -0.1 & 1.07 & 461 & -0.01 & 1.08 & 466 & $12.4 \%$ & $-0.09[-0.23,0.05]$ & & \\
\hline Schernthaner $G, 2013$ & 0.03 & 1.15 & 365 & 0.06 & 1.13 & 353 & $8.5 \%$ & $-0.03[-0.20,0.14]$ & & \\
\hline Wilding JP, 2013 & -0.14 & 1.2 & 144 & 0.03 & 1.16 & 134 & $3.1 \%$ & $-0.17[-0.45,0.11]$ & & \\
\hline Subtotal $(95 \% \mathrm{Cl})$ & & & 970 & & & 953 & $24.0 \%$ & $-0.08[-0.18,0.02]$ & $\mathbf{v}$ & 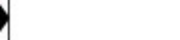 \\
\hline Heterogeneity: $\mathrm{Chi}^{2}=0$ & $77, \mathrm{df}=2$ & $2(P=0$ & $68) ; 1^{2}$ & $=0 \%$ & & & & & & \\
\hline Test for overall effect: $z$ & $=1.56(\mathrm{P}$ & $=0.12$ & & & & & & & & \\
\hline Total $(95 \% \mathrm{Cl})$ & & & 3448 & & & 3309 & $100.0 \%$ & $-0.10[-0.15,-0.05]$ & 4 & \\
\hline $\begin{array}{l}\text { Heterogeneity: } \mathrm{Chi}^{2}= \\
\text { Test for overall effect: } 2\end{array}$ & $\begin{array}{l}.57, \mathrm{df}= \\
=4.09(\mathrm{P}\end{array}$ & $\begin{array}{l}19(P= \\
0<0.00\end{array}$ & $\begin{array}{l}=0.42) ; \\
\text { 101) }\end{array}$ & $i^{2}=39$ & & & & & $\begin{array}{cc}1 & 1 \\
-1 & -0.5 \\
\text { decreased } \mathrm{TG}\end{array}$ & $\begin{array}{lll}0 & 0.5 & 1 \\
0\end{array}$ \\
\hline
\end{tabular}

Figure 3a. Forest plot depicting the TG level with canagliflozin versus control group. 


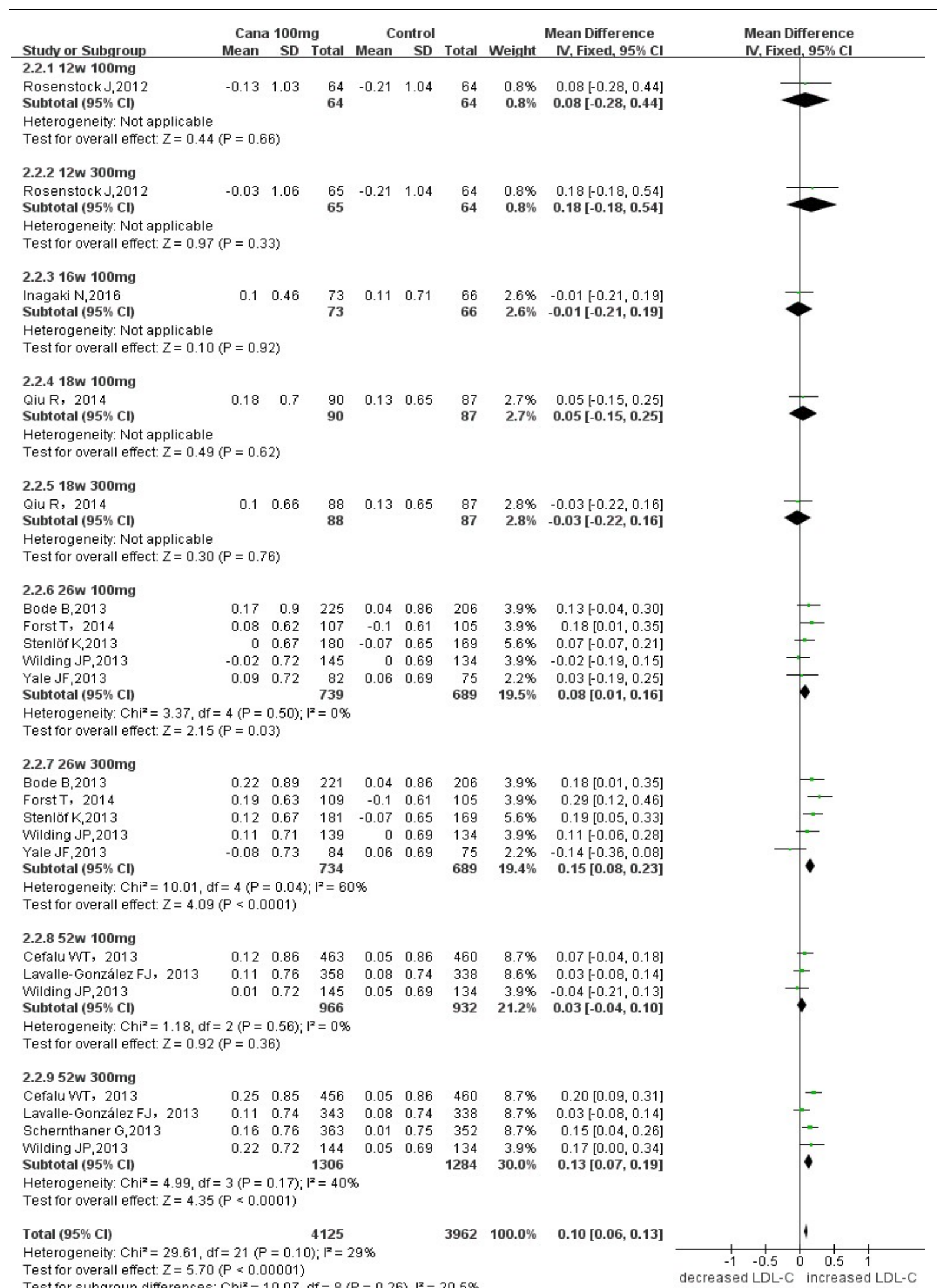

Figure 3b. Forest plot depicting LDL-C with canagliflozin versus control group. 




Figure 3c. Forest plot depicting HDL-C with canagliflozin versus control group. 
It is well known that meta-analysis has certain unavoidable limitations. Although we had limited this analysis to well designed RCTs and performed quality assessment to reduce the possible selective bias, the present meta-analysis still had several potential limitations. First, this meta-analysis compared canagliflozin with placebo and other active antidiabetic drugs because the active controlled trials were so few to conduct a metaanalysis. Second, the data of liver biopsy, which is essential for the diagnosis of non-alcoholic fatty liver disease/non-alcoholic steatohepatitis (22), is insufficient. It is hard to obtain in current pulished studies.

\section{CONCLUSION}

We conduct a meta-analysis on canagliflozin effect on fatty liver indexes in T2DM patients. Our results showed canagliflozin decreased serum concentrations of ALT, AST, GGT, TG but increased LDL and HDL cholesterol levels at week 26 or 52. Our results indicated that canagliflozin may have a protective effect on fatty liver. The limitation was that liver biopsy was hard to obtain. More RCTs specified on NAFLD are expected to make further conclusion.

\section{ACKNOWLEDGEMENTS}

This work was supported by Beijing Natural Science Foundation of China (Grants no. 7174308)

\section{REFERENCES}

1. Inzucchi SE, Bergenstal RM, Buse JB, Diamant M, Ferrannini E, Nauck $\mathrm{M}$ et al. Management of hyperglycemia in type 2 diabetes, 2015: a patientcentered approach: update to a position statement of the American Diabetes Association and the European Association for the Study of Diabetes. Diabetes Care, 2015; 38(1): 140-149.

2. Buzzetti E, Pinzani M, Tsochatzis EA. The multiplehit pathogenesis of non-alcoholic fatty liver disease (NAFLD). Metabolism, 2016; 65(8):1038-1048.

3. Richard J, Lingvay I. Hepatic steatosis and Type 2 diabetes: current and future treatment considerations. Expert Rev Cardiovasc Ther, 2011; 9(3):321-328.

4. Mills EP, Brown KPD, Smith JD, Vang PW, Trotta K. Treating nonalcoholic fatty liver disease in patients with type 2 diabetes mellitus: a review of efficacy and safety. Ther Adv Endocrinol Metab, 2018; 9(1):15-28.

5. Avranas K, Imprialos K, Stavropoulos K, Lales G, Manafis A, Skalkou A et al. Sodium-glucoser cotransporter 2 inhibitors: glucose lowering against other hypoglycemic agents. Cardiovasc Hematol
Disord Drug Targets, 2018; doi: 10.2174/1871529X18666180206160838.

6. Devineni D ML, Hompesch M, Skee D, Vandebosch A, Murphy J, Ways K, Schwartz S. Canagliflozin improves glycaemic control over 28 days in subjects with type 2 diabetes not optimally controlled on insulin. Diabetes Obes Metab, 2012; 14(6):539-545.

7. Sha S DD, Ghosh A, Polidori D, Chien S, Wexler D, Shalayda K, Demarest K, Rothenberg P. Canagliflozin, a novel inhibitor of sodium glucose co-transporter 2, dose dependently reduces calculated renal threshold for glucose excretion and increases urinary glucose excretion in healthy subjects. Diabetes Obes Metab, 2011; 13(7):669-672.

8. Tahara A, Kurosaki E, Yokono M, Yamajuku D, Kihara R, Hayashizaki Y et al. Effects of SGLT2 selective inhibitor ipragliflozin on hyperglycemia, hyperlipidemia, hepatic steatosis, oxidative stress, inflammation, and obesity in type 2 diabetic mice. Eur J Pharmacol, 2013; 715:246-255.

9. Suzuki M, Takeda M, Kito A, Fukazawa M, Yata T, Yamamoto $\mathrm{M}$ et al. Tofogliflozin, a sodium/glucose cotransporter 2 inhibitor, attenuates body weight gain and fat accumulation in diabetic and obese animal models. Nutr Diabetes, 2014; doi: 10.1038/nutd.2014.20.

10. Shiba K TK, Komiya C, Miyachi Y, Mori K, Shimazu N, Yamaguchi S, Ogasawara N, Katoh M, Itoh M, Suganami T, Ogawa Y. Canagliflozin, an SGLT2 inhibitor, attenuates the development of hepatocellular carcinoma in a mouse model of human NASH. Sci Rep, 2018; doi: 10.1038/s41598-01819658-7.

11. Seko Y, Sumida Y, Tanaka S, Mori K, Taketani H, Ishiba $\mathrm{H}$ et al. Effect of sodium glucose cotransporter 2 inhibitor on liver function tests in Japanese patients with non-alcoholic fatty liver disease and type 2 diabetes mellitus. Hepatol Res, 2017; 47(10):10721078.

12. Takase T, Nakamura A, Miyoshi H, Yamamoto C, Atsumi T. Amelioration of fatty liver index in patients with type 2 diabetes on ipragliflozin: an association with glucose-lowering effects. Endocr J, 2017; 64(3):363-367.

13. Yang XP LD, Zhong XY, Shen HP, Huang YL. Efficacy and safety of canagliflozin in subjects with type 2 diabetes: systematic review and meta-analysis. Eur J Clin Pharmacol, 2014; 70(10):1149-1158.

14. Xiong W XM, Zhang M, Chang F. Efficacy and safety of canagliflozin in patients with type 2 diabetes: A meta-analysis of randomized controlled trials. Medicine (Baltimore), 2016; doi: 10.1097/MD.0000000000005473.

15. Storgaard H GL, Bennett C, Grøndahl MF, Christensen MB, Knop FK, Vilsbøll T. Benefits and Harms of Sodium-Glucose Co-Transporter 2 Inhibitors in Patients with Type 2 Diabetes: A Systematic Review and Meta-Analysis. PLoS One, 2016; doi: 10.1371/journal.pone.0166125. 
16. Higgins J, Green S. Cochrane Handbook for Systematic Reviews of Interventions Version 5.1.0. 2014. Available from www.cochrane -handbook.org.

17. Gonzalez-Cantero J, Martin-Rodriguez JL, Gonzalez-Cantero A, Arrebola JP, Gonzalez-Calvin JL. Insulin resistance in lean and overweight nondiabetic Caucasian adults: Study of its relationship with liver triglyceride content, waist circumference and BMI. PLoS ONE, 2018; doi: 10.1371/journal.pone.0192663.

18. Pérez-Martínez L O-CL, Rubio-Mediavilla S, Narro J, Bernardo I, Oteo JA, Blanco JR. Maraviroc improves hepatic triglyceride content but not inflammation in a murine nonalcoholic fatty liver disease model induced by a chronic exposure to highfat diet. Transl Res, 2018; doi: 10.1016/j.trsl.2018.01.004.

19. EASL-EASD-EASO Clinical Practice Guidelines for the management of non-alcoholic fatty liver disease. J Hepatol, 2016; 64(6):1388-1402.

20. Briand F ME, Brousseau E, Burr N, Urbain I, Costard C, Mark M, Sulpice T. Empagliflozin, via Switching Metabolism Toward Lipid Utilization, Moderately Increases LDL Cholesterol Levels Through Reduced LDL Catabolism. Diabetes, 2016; 65(7):2032-2038.

21. Hayashi T FT, Nakanishi N, Yamamoto S, Tomoyasu M, Osamura A, Ohara M, Yamamoto T, Ito Y, Hirano T. Dapagliflozin decreases small dense low-density lipoprotein-cholesterol and increases high-density lipoprotein 2-cholesterol in patients with type 2 diabetes: comparison with sitagliptin. Cardiovasc Diabetol, 2017; doi: 10.1186/s12933-016-0491-5.

22. P B. Diagnosis of non-alcoholic fatty liver disease/non-alcoholic steatohepatitis: Why liver biopsy is essential. Liver Int, 2018; doi: 10.1111/liv. 13653. 
J Pharm Pharm Sci (www.cspsCanada.org) 21, 222 - 235, 2018

\begin{tabular}{|c|c|c|c|c|c|c|c|c|}
\hline $\begin{array}{l}\text { Studies } \\
\text { (Author, year) }\end{array}$ & CANA & Control & $\mathbf{N}$ & $\begin{array}{l}\text { Background } \\
\text { therapy }\end{array}$ & $\begin{array}{l}\text { Mean Age } \\
\text { (year) }\end{array}$ & $\begin{array}{l}\text { Race } \\
\text { (Primary) }\end{array}$ & $\begin{array}{l}\text { Mean HbA1c } \\
(\%)\end{array}$ & $\begin{array}{l}\text { Follow-up } \\
\text { (weeks) }\end{array}$ \\
\hline Bode B, 2013 & $\begin{array}{l}\text { CANA: } 100 \mathrm{mg} \text {; } \\
300 \mathrm{mg}\end{array}$ & PLA & 714 & OAD & 63.6 & White & 7.7 & 26 \\
\hline Cefalu WT, 2013 & $\begin{array}{l}\text { CANA } 100 \mathrm{mg} \\
300 \mathrm{mg}\end{array}$ & GLIM & 1450 & MET & 56.2 & White & 7.8 & 52 \\
\hline Forst T, 2014 & $\begin{array}{l}\text { CANA: } 100 \mathrm{mg} \text {; } \\
300 \mathrm{mg}\end{array}$ & PLA & 342 & $\mathrm{MET}+\mathrm{PIOG}$ & 57.4 & White & 7.9 & $26 / 52$ \\
\hline Inagaki N,2016 & CANA: $100 \mathrm{mg}$ & PLA & 146 & INS & 58.0 & Japanese & 8.9 & 16 \\
\hline $\begin{array}{l}\text { Lavalle-González FJ, } \\
2013\end{array}$ & $\begin{array}{l}\text { CANA: } 100 \mathrm{mg} \text {; } \\
300 \mathrm{mg}\end{array}$ & $\begin{array}{l}\mathrm{PBO} / \text { SITA } \\
100 \mathrm{mg}\end{array}$ & 1119 & MET & 55.4 & White & 7.9 & 52 \\
\hline Qiu R， 2014 & $\begin{array}{l}\text { CANA } 100 \mathrm{mg} \\
300 \mathrm{mg}\end{array}$ & PLA & 279 & MET & 57.4 & White & 7.6 & 18 \\
\hline Rosenstock J,2012 & $\begin{array}{l}\text { CANA } 100 \mathrm{mg} \\
300 \mathrm{mg}\end{array}$ & SITA $100 \mathrm{mg}$ & 451 & MET & 52.9 & White & 6.0 & 12 \\
\hline Schernthaner G, 2013 & CANA: $300 \mathrm{mg}$ & SITA 100mg & 756 & $\mathrm{MET}+\mathrm{SU}$ & 56.7 & White & 8.1 & 52 \\
\hline Stenlöf K,2013 & $\begin{array}{l}\text { CANA: } 100 \mathrm{mg} \\
300 \mathrm{mg} \\
\text { CANA: } 100 \mathrm{mg} \\
300 \mathrm{mg}\end{array}$ & $\begin{array}{l}\text { PLA } \\
\text { PBO/ SITA } \\
100 \mathrm{mg}\end{array}$ & 1664 & Diet and exercise & 55.4 & White & 8.0 & $\begin{array}{l}26 \\
52\end{array}$ \\
\hline Wilding JP,2013 & $\begin{array}{l}\text { CANA } 100 \mathrm{mg} \\
300 \mathrm{mg}\end{array}$ & PLA & 469 & $\mathrm{MET}+\mathrm{SU}$ & 56.8 & White & 8.1 & $26 / 52$ \\
\hline Yale JF,2013 & $\begin{array}{l}\text { CANA } 100 \mathrm{mg} ; \\
300 \mathrm{mg}\end{array}$ & PLA & 269 & SU or INS & 68.5 & White & 8.0 & 52 \\
\hline
\end{tabular}


J Pharm Pharm Sci (www.cspsCanada.org) 21, 222 - 235, 2018

Table 2. Baseline liver function and lipid levels of included studies

\begin{tabular}{|c|c|c|c|c|c|c|c|c|c|c|}
\hline \multirow[t]{2}{*}{$\begin{array}{l}\text { Studies } \\
\text { (Author, year) }\end{array}$} & \multirow[t]{2}{*}{ Treatments } & ALT & AST & GGT & ALP & \multirow[t]{2}{*}{ TG } & \multirow[t]{2}{*}{ LDL-C } & \multirow{2}{*}{$\begin{array}{c}\text { HDL-C } \\
\mathrm{mmol} / \mathrm{L}\end{array}$} & \multirow[t]{2}{*}{ LDL/HDL } & \multirow[t]{2}{*}{$\begin{array}{l}\text { Non-HDL } \\
\text { cholesterol }\end{array}$} \\
\hline & & \multicolumn{4}{|c|}{$\mathbf{U} / \mathbf{L}$} & & & & & \\
\hline \multirow[t]{3}{*}{ Bode B, (2013) } & PLA & 28.6 & 25.2 & 43.1 & 72.3 & $1.7(0.9)$ & $2.4(0.9)$ & $1.3(0.3)$ & $2.0(0.9)$ & $3.2(1.0)$ \\
\hline & CANA $100 \mathrm{mg}$ & 26.0 & 22.4 & 32.0 & 72.2 & $1.8(1.2)$ & $2.4(1.0)$ & $1.2(0.3)$ & $2.0(0.9)$ & $3.2(1.1)$ \\
\hline & CANA $300 \mathrm{mg}$ & 26.6 & 23.7 & 29.5 & 70.9 & $1.7(1.1)$ & $2.3(0.8)$ & $1.2(0.3)$ & $2.1(0.9)$ & $3.1(1.0)$ \\
\hline \multirow[t]{3}{*}{ Cefalu WT, 2013} & GLIM & $29.2(17.1)$ & $23.7(10.9)$ & $37.8(36.3)$ & $73.2(21.6)$ & $1.9(1.2)$ & $2.7(0.9)$ & $1.2(0.3)$ & $2.3(0.9)$ & $3.5(1.0)$ \\
\hline & CANA $100 \mathrm{mg}$ & $29.8(16.1)$ & $24.3(11.0)$ & $41.9(59.7)$ & $73.6(21.2)$ & $2.1(1.5)$ & $2.6(0.9)$ & $1.2(0.3)$ & $2.3(0.9)$ & $3.5(1.0)$ \\
\hline & CANA $300 \mathrm{mg}$ & $28.9(16.7)$ & $23.5(10.8)$ & $37.0(30.4)$ & $72.6(20.5)$ & $2.1(2.1)$ & $2.8(0.9)$ & $1.2(0.3)$ & $2.4(0.9)$ & $3.7(1.1)$ \\
\hline \multirow[t]{3}{*}{ Forst T, 2014} & PLA & 22.5 & & 26.0 & & $1.6(1.0)$ & $2.5(0.9)$ & $1.3(0.3)$ & $2.1(0.9)$ & $3.2(1.0)$ \\
\hline & CANA $100 \mathrm{mg}$ & 25.9 & & 29.9 & & $1.7(1.1)$ & $2.4(0.9)$ & $1.3(0.3)$ & $2.0(0.8)$ & $3.2(1.0)$ \\
\hline & CANA $300 \mathrm{mg}$ & 21.9 & & 29.3 & & $1.6(1.1)$ & $2.3(0.8)$ & $1.4(0.3)$ & $1.8(0.7)$ & $3.0(1.0)$ \\
\hline \multirow[t]{2}{*}{ Inagaki N,2016 } & PLA & $23.5(11.7)$ & $25.1(11.2)$ & $43.9(57.7)$ & & $1.6(1.3)$ & $3.2(0.7)$ & $1.5(0.4)$ & & \\
\hline & CANA $100 \mathrm{mg}$ & $25.9(19.0)$ & $27.3(11.9)$ & $35.0(29.4)$ & & $1.4(1.3)$ & $3.2(0.9)$ & $1.6(0.1)$ & & \\
\hline Lavalle-González & $\mathrm{PBO} /$ & 30 & 24 & & & $2.0(1.1)$ & $2.8(0.9)$ & $1.2(0.3)$ & $2.6(1.0)$ & $3.7(1.0)$ \\
\hline \multirow[t]{2}{*}{ FJ, 2013} & $100 \mathrm{mg}$ & 30 & 24 & & & $2.2(1.6)$ & $2.8(0.8)$ & $1.2(0.3)$ & $2.5(0.9)$ & $3.8(1.1)$ \\
\hline & $\begin{array}{l}\text { CANA } 100 \mathrm{mg} \\
\text { CANA } 300 \mathrm{mg}\end{array}$ & 30 & 24 & & & $2.1(1.5)$ & $2.8(0.9)$ & $1.2(0.3)$ & $2.4(0.9)$ & $3.7(1.0)$ \\
\hline \multirow[t]{3}{*}{ Qiu R， 2014} & PLA & & & & & $2.0(1.3)$ & $2.6(1.1)$ & $1.2(0.3)$ & $2.2(0.9)$ & $3.5(1.2)$ \\
\hline & CANA $100 \mathrm{mg}$ & & & & & $1.9(0.8)$ & $2.8(1.0)$ & $1.2(0.3)$ & $2.4(0.9)$ & $3.7(1.1)$ \\
\hline & CANA $300 \mathrm{mg}$ & & & & & $2.2(1.7)$ & $2.7(0.9)$ & $1.3(0.3)$ & $2.2(0.8)$ & $3.7(1.1)$ \\
\hline \multirow[t]{3}{*}{ Rosenstock J,2012 } & SITA $100 \mathrm{mg}$ & & & & & $1.8(0.1)$ & & $1.2(0.04)$ & $2.9(0.1)$ & \\
\hline & CANA $100 \mathrm{mg}$ & & & & & $2.0(0.1)$ & & $1.2(0.04)$ & $2.9(0.1)$ & \\
\hline & CANA $300 \mathrm{mg}$ & & & & & $2.0(0.2)$ & & $1.2(0.04)$ & $2.7(0.1)$ & \\
\hline Schernthaner & SITA $100 \mathrm{mg}$ & 26.3 & & & & $1.9(1.3)$ & $2.5(0.9)$ & $1.2(0.3)$ & $2.2(0.9)$ & $3.3(1.0)$ \\
\hline $\mathrm{G}, 2013$ & CANA $300 \mathrm{mg}$ & 28.0 & & & & $2.1(1.4)$ & $2.6(1.0)$ & $1.2(0.3)$ & $2.3(0.9)$ & $3.5(1.1)$ \\
\hline \multirow[t]{3}{*}{ Stenlöf K,2013 } & PLA & 26.9 & & & 78.8 & $2.2(1.2)$ & $3.1(1.1)$ & $1.1(0.3)$ & $2.9(1.3)$ & $4.1(1.2)$ \\
\hline & CANA $100 \mathrm{mg}$ & 27.5 & & & 81.6 & $2.0(1.2)$ & $3.1(1.0)$ & $1.2(0.3)$ & $2.7(1.0)$ & $3.9(1.0)$ \\
\hline & CANA $300 \mathrm{mg}$ & 28.9 & & & 82.5 & $2.0(1.1)$ & $2.9(0.9)$ & $1.2(0.3)$ & $2.6(0.9)$ & $3.7(1.0)$ \\
\hline \multirow[t]{3}{*}{ Wilding JP,2013 } & PLA & 28.6 & & & & $2.2(1.5)$ & $2.8(1.0)$ & $1.2(0.3)$ & $2.4(0.9)$ & $3.8(1.2)$ \\
\hline & CANA $100 \mathrm{mg}$ & 29.4 & & & & $2.1(1.3)$ & $2.7(1.1)$ & $1.2(0.3)$ & $2.4(1.1)$ & $3.6(1.3)$ \\
\hline & CANA $300 \mathrm{mg}$ & 29.7 & & & & $2.3(1.5)$ & $2.6(0.9)$ & $1.1(0.3)$ & $2.4(0.9)$ & $3.7(1.1)$ \\
\hline \multirow[t]{2}{*}{ Yale JF,2013 } & PLA & 23.7 & 23.6 & & 79.3 & $2.0(1.1)$ & $2.5(1.0)$ & $1.1(0.3)$ & $2.3(1.0)$ & $3.4(1.1)$ \\
\hline & CANA $100 \mathrm{mg}$ & 20.8 & 21.9 & & 77.8 & $1.9(0.9)$ & $2.4(0.9)$ & $1.1(0.2)$ & $2.2(0.9)$ & $3.2(0.9)$ \\
\hline
\end{tabular}


J Pharm Pharm Sci (www.cspsCanada.org) 21, 222 - 235, 2018

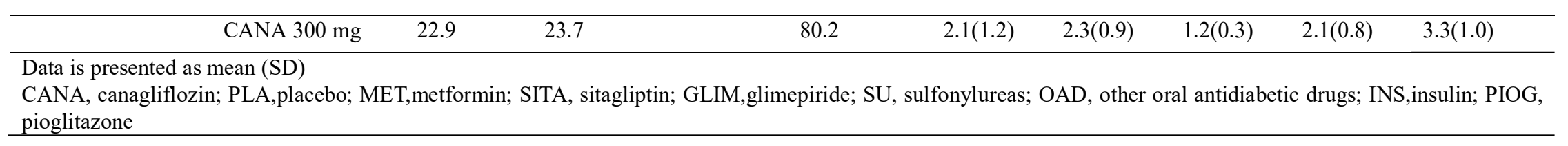

